\title{
Convergence of architectural, visual and climate data
}

\author{
F. Klassen \\ Faculty of Communication and Design, Ryerson University, Canada
}

\begin{abstract}
The relationship between buildings and image, both static and moving, has occupied a significant role throughout architectural history. Current innovations in materials research, digital technology and lighting are strengthening this connection as a vital idea permeating image arts and built spaces. The objective of this paper is to expand the intersection of architecture and image within the context of climate change. As the recent kinetic art and media facades as well as the author's own prototypes highlight, this emergent practice promotes climate conscious interactive systems and sustainable illumination that are integrated into building surfaces. While responding to changes in environmental variables and illuminating the building with renewable energy sources, this alternative approach also emphasizes developing a social and environmental narrative for the use of media facades, challenging the current application for mainly commercial advertising. The author's own climate responsive prototypes reveal the methodological experimentation with weather elements of snow, rain, light and wind. The three-tiered display of collected climactic information lead to integration of various technologies to make the elements visible, harvest and generate energy from their kinetic movement. This paper will present conclusions drawn from the previous experimentation, as well as a new direction to eliminate additional light pollution while integrating architectural and climate visualization with the sustainable media façade technology in built environments.
\end{abstract}

Keywords: architecture, climate, media facades, materials' research.

\section{Introduction: architecture changes climate}

There appears to be a disparity between public perception of the causes of climate change and the building industry's contribution to it as a whole, especially with 
increasing greenhouse gas emissions at unprecedented rates. According to the U.S. Energy Information Administration (EIA), the building sector consumes seventyfive percent $(74.9 \%)$ of all electricity produced for the operation of buildings in the U.S. and globally, these percentages are even higher. The building sector was responsible for nearly half $(44.6 \%)$ of the U.S. $\mathrm{CO}_{2}$ emissions in 2010. By comparison, transportation accounts for $34.3 \%$ of $\mathrm{CO}_{2}$ emissions and industry just $21.1 \%$ [1] although they are advertised to be the main culprits of climate change in the general media.

The building industry's impact on climate change as a subject needs to be better understood and communicated not only to fully inform all constituents but to reshape the general perceptions of how we can be proactive and break out of the negative cycle of contribution in our cities. Naomi Klein [2], author of the book entitled 'This changes everything: Capitalism vs. the climate', eloquently frames that although 'we lack the collective spaces in which to confront the raw terror of ecocide', there are no shortage of 'potential sparks' for those seeking resolutions. Global warming and its implications on us as 'world citizens' indeed spark many new debates and innovations through social, economic, cultural and scientific activity. The issues are discussed widely in popular media with artists, designers, architects, activists, engineers, and politicians who are proactive and take action to lessen effects of climate change. These discussions are necessary to extrapolate the relationship of architecture and climate change all around the world. Perhaps then the construction activity can be pushed beyond the domain of experts' or critics' views of the current or upcoming building stock and their critique as an aesthetic and/or technical pursuit.

David Buckland [3] an artist and climate change activist, creates a cultural discourse by taking artists, scientists, engineers, writers, architects, and musicians to the arctic, the hot bed of climate change. He hopes that the work generated from this immediate experience of the disappearing icecap instigate an attitude shift towards climate change despite the general perception of it being a difficult issue for us as a society to deal with. Buckland thinks that solutions to climate change will not be generated just from the political, economic or scientific circles but that local arts/cultural sector will be instrumental in trickling positive change through all aspects of society. An example is the novel 'Solar' by world re-known author Ian McEwan [4], written after his trip to the arctic, where he satirically weaves one man's ambitions and self-deceptions on climate change. He, while writing about his own experiences in the arctic, also ponders whether this is the 'beginning of the end, or end of the beginning' of a new era and observes that ' $[t]$ he pressure of our numbers, the abundance of our inventions, the blind forces of our desires and needs are generating a heat, the hot breath of our civilization...' (Buckland [3]). Ian McEwan's projections also concur with David Suzuki's, Co-Founder of the David Suzuki Foundation, and an award-winning scientist, environmentalist and broadcaster. "Eighty percent of us now live in an urban setting, and I think that the solution to our environmental problems is not to say 'we've got to break down cities and get everybody back to the land' - that would be disastrous - but we have to make cities our major habitat...we have to make them more in balance, I think, with the rest of the things that keep us alive" [5]. Our cities have to be the 
test bed of energy conscious design initiatives and challenge the status quo of building methods since majority of world population live in urban settings.

I believe that the intersection of architecture, image arts, and climate change brings to view our buildings and cities, the 'hot breadth of our civilization', as the underlying threats amplifying global warming. Emerging practice of sustainable media facades, as exemplified in the following case studies, provide a paramount vehicle to reach out to the public consciousness, without being didactic, and propel positive change in the direction that aligns with building environmental stewardship while at the same time question our energy dependency and consumption in architecture.

\section{Context: architecture and image}

Throughout the nineteenth century, architectural critics have frequently sought connections with other creative fields such as art, sculpture, music and literature to place building design and construction activity in a wider cultural context. This has led to many erroneous interpretations of architecture as a visual construct, a mere static form making exercise throughout various historical periods. However, the search for a meaningful building practice still continues today in the twentyfirst century. Juhani Pallasmaa, an influential architectural theorist, reaffirms an important but ignored connection between the role of the body and the senses in his book 'The Eyes of the Skin - Architecture and the Senses' [6]. He has been instrumental debating in his essays that every moving experience of built environments is multi-sensory and therefore architecture has to engage not just the vision but all of our haptic system. In his book entitled 'The Architecture of Image: Existential Space in Cinema' he elaborates on the discovery of buildings through the eyes of a media specialist or film maker, as a necessary method to establish a new 'mental ground of architecture' [7].

Although overall design and fabrication of 'static form' still dominate the process of making buildings, the architectural debate now emphasizes 'responsive strategies' that align with the environmental conditions and user interaction including all our sensory experiences. Design ideals of modernism and the convenient climate control in buildings have long been challenged in architecture but particularly intensified since the early nineties. The linkages between increased building performance and enhanced material properties are leading the new methods of rationalization and thus resulting in a different 'active' expression. Coined as 'performance-oriented design' [8], this approach is currently leading the twenty-first century architectural discourse and suited for finding a new formal, technological, material and visual expression while improving the energy and climate responsiveness of buildings. Scientific research is continually improving the mechanical, thermal, electrical, chemical and optical properties of building materials and integrated systems in architecture. Therefore, it seems obsolete to practice architectural form making and its associated materiality solely based on visual properties in conception of spaces. It becomes relevant to find out how a building may perform and respond to variables in climactic conditions over time while enhancing our all-sensory experiences in spaces we inhabit. 
In his book 'Made to Measure', Philip Ball [9] predicts that there will be always room for so-called 'dumb' i.e. static materials that do not change their properties or display their changing characteristics. Nevertheless, it will increasingly pay to be 'smart' in the manner discussed above, although he maintains that this is still not nearly sufficient. In the future, material scientists hope that materials will be developed that are able to take into account changes, maintaining 'a memory of what has transpired before and that learn from these previous experiences' and becoming more active and 'smarter' or 'intelligent' as they get older. Many experiments in energy generating building skins that also integrate media facades provide more articulated materials and building systems that are active. An example of such material is the media glass or LED mesh that is capable of receiving video signals. This is enabled by use of advanced and integrated technologies that shifts the centuries old perception of static materials serving architectural form towards active materials leading formal/ visual expression. In doing so, buildings are also capable of creating moving/changing images in direct response to the environmental conditions they are situated in.

'This century belongs to light' wrote László Moholy-Nagy [10], an artist, photographer and architectural theorist of the Bauhaus, in his book 'The New Vision: From Material to Architecture' in 1932. Our dependency on nonrenewable energy sources today proves the fact that the last century did in fact belong to 'artificial light'. Given the context of climate change, increasing greenhouse gas emissions from all major urban centers globally, and the opposite surge for alternative experiments for building lighting, heating, and cooling systems, we can say that twenty-first century may belong to improved 'building performance' and its visual articulation.

\section{Precedents in art and architecture}

'Artists are geniuses who serve as early warning systems for changes in society's sensory balance' Marshall McLuhan [11].

Artists who engage with weather elements, climate change and passage of time in their creations continue to inspire architects and engineers who are generating the new vocabulary for 'performance oriented' buildings. Danish artist and photographer, Olafur Eliasson [12], re-creates the elements of weather, such as the sun, rain, mist, and light reflection in his installations, that one would normally experience outside, and brings them inside a gallery and successfully merges them with existing building surfaces or creates new architectural experiences all together. He amplifies the spatial effects of the constructed weather elements and highlights their transition in a void space or reflects them on to the gallery walls. Thus he makes the viewers take their time and observe the changes of the elements at length, rather than leaving with a brief moment of observation as one would outside. Always maintaining a discourse about weather, consumerism and architectural spectacle, he draws viewers' attention to the surrounding natural context in his installations such as in 'the Glacierhouse Effect versus the Greenhouse Effect' (Santa Fe, 2005), 'The Weather Project' (London, 2003), and Double Sunset billboard (Utrecht, 1999) [13]. Olafur Eliasson recently designed a 
multi-faceted glass screen for the Harpa Reykjavik Concert Hall and Conference Center [14], in collaboration with Henning Larsen Architects in 2011. Modulating the changing light conditions around the building, the design is based on the geometric principle reminiscent of the crystalized basalt columns commonly found in Iceland. Using the crystalized basalt material properties as inspiration, his design for the southern façade creates kaleidoscopic reflections of the city and surrounding landscape that dramatically alters the transparency, reflectivity, and color of the building as the weather and seasons change. The re-purposed geometry of the basalt crystal facade modules contain LED lights, the brightness and color of which can be controlled, that make the building glow long after the sunset. Although the design relies on powering the LEDs through electricity, integrated sensor technology minimizes the energy consumption by adjusting the required visible levels according to the brightness of the surrounding environment rather than keeping the building lit the same throughout the day, month and year.

Ned Khan [15] is another artist who is inspired by natural phenomena, such as the wind, water and fire, whose installations operate at the convergence of art, architecture and weather. His kinetic building facades create a direct interface between the installation and the natural environment, typically providing sitespecific references to iconic natural features of a city. One of San Francisco's greenest buildings, the Public Utilities Commission (PUC) headquarters is an interactive installation built in collaboration with KMD Architecture. 'Firefly' installation reveals rippling patterns during the day when the 5 inch-squarehinged-clear polycarbonate panels swing with the wind. Each panel has a smallembedded magnet that connects with an electrical reed switch and the back and forth swinging action triggers the flickering of tiny LED lights mimicking fireflies. Thus, the installation draws public attention to a threatened species, fireflies, due to the destruction/erosion of riparian ecosystem; the wet soil bordering along riverbanks, streams, creeks, or other water networks. The illumination of this entire sculpture requires less energy than a 75-watt light bulb and serves as kinetic framework for a series of vertical axis wind turbines that supply power to the building.

BIG's (Bjarke Ingels Group) new Waste-to-Energy plant [16], slated to open in 2017, provides an exemplary architectural model in the field of waste management and energy production, as well as being a landmark in the cityscape of Copenhagen. The public art component of the project, the Big Vortex, is conceptualized by Berlin-based artists 'realities: united' [17] to give the city a visual message for what a ton of carbon-dioxide $\left(\mathrm{CO}_{2}\right)$ emissions look like. The modified smokestack acts as a gentle reminder of the residues of waste burning and its contributions to climate change. The troidal-vortex shaped gas clouds in the shape of smoke rings appear as they leave the smokestack and become visible due to the condensation of water in the flue gases as they slowly rise and cool, before slowly dissolving into the air. Each smoke ring, approximately 30 meters in diameter and 3 meters in height, constitutes exactly one ton of fossil carbon dioxide. By making the waste visible, the rather abstract $\mathrm{CO}_{2}$ emissions that contribute to climate change become something the people living in Copenhagen can see, relate to and act on by minimizing their contribution through 
consumption. At night, heat-tracking lights will be used to position lasers onto the smoke rings turning them into glowing artworks over the city.

The next generation kinetic architectural facades and use of materials that can respond to various environmental and functional conditions required or desired by occupants in a space proposes a big challenge for many architects and designers. Michelle Addington and Daniel Schodek [18], authors of 'Smart Materials and Technologies', suggest that '...by investigating the transient behavior of the material, we [can] challenge the privileging of the static planar surface' that long dominated the architectural vision. They further propose that '[s]mart materials, with their transient behavior and ability to respond to energy stimuli, may eventually enable the selective creation and design of an individual's sensory experiences'. Although they conclude that architects are not in a position to exploit this alternative paradigm shift in life-scale buildings yet, innovative ideas are being experimented at prototypical scales. SmartWrap ${ }^{\mathrm{TM}}$ project and its following iterations of architectural prototypes by KieranTimberlake Associates LLP [19], are poignant case studies in this area. We are used to seeing plastic film for wrapping food, as plastic bags, or bottles for water and soft drinks. In this prototype, a composite plastic film is envisioned for wrapping a space, thus the coining of the term 'SmartWrap'TM' [20].

Rather than simply assembling existing materials to construct an exterior wall, the architects researched and built a prototypical cladding material that is made of commonly known PET plastic (polyethylene terephthalate, used in water bottles). This exterior cladding material, SmartWrap ${ }^{\mathrm{TM}}$, incorporates emerging technologies in heating, cooling (through embedded micro-capsules of phase change materials), visual display, lighting (through organic light emitting diodes deposited on to plastic substrate), and energy collection (through integrated silicon solar cells). Thus the building skin acts as an ideal solar collector, moderates temperatures and also provides lighting and information displays that can be masscustomizable. Further, the possibility of positioning a window wherever occupants want on a building facade or interior room offers endless possibilities between the interior and exterior, constantly animating the building facade. The technology transfer that the architects envision for this building cladding material takes its cues from current ink-jet printing developments; integrating material deposition and patterning by solution processing and thus placing electronic display and lighting functions directly onto the hybrid and flexible plastic substrate. This continuous, roll-to-roll printing process is compatible with large size requirements in construction although the current available technology is limited to small size applications.

Simone Giostra \& Partners [21] have acquired a reputation for advancing the boundaries of building performance in a similar fashion, particularly in the areas of integrated energy technology and media façade application in buildings. They claim that their 'objective is to bring an emerging digital design culture to bear on the way buildings are designed, manufactured and installed, resulting in structural, thermal, and energy efficiency in buildings, and in a radical new language in architecture'. SOLPIX [22] is a solar powered sun shading and media wall system created in collaboration with Permateelisa, a company specialising in building 
cladding systems. Featuring large-scale colour LED display and photovoltaic panels integrated on to horizontal or vertical sun-shading systems, SOLPIX transforms the existing glass structure into an energy generating façade. The facade harvests solar energy during the day and protects the building interior from excessive solar radiation while powering the media screen at the same time. The project is based on the earlier experimentation for GreenPix, a zero energy media wall, designed for the Xicui Entertainment Complex in Beijing in 2008. Developed in collaboration with British engineers Arup and manufacturers Suntech and Thorn Lighting, it features one of the largest colour LED displays and the first photovoltaic system integrated into a glass curtain wall at the time. This system monitors its own performance and visualizes it in motion graphics that play across the façade. In addition to other digital displays, the wall also serves as a type of weather report; sensors placed between the glass panels register variations in wind pressure and solar exposure, and use embedded software to create realtime interactive animations that transform the building façade into a responsive environment. The Giostra \& Partners are pushing this technology in SOLPIX and improving the energy efficiency of GreenPix, while increasing the resolution of the digital display of the transparent media wall.

This sustainable digital-media space offers many new possibilities for integrating art, climate and architecture in an urban context. It makes an attempt to redefine the use of media as a catalyst between built and natural environment and its change rather than sufficing with commercial advertising for content. Aside from the potential for the façade to display climactic information, an obvious downside is the danger of creating additional light pollution in cities that needs to be further researched as it potentially could counteract the benefits of this green media façade technology.

\section{Weathering architecture prototypes, findings and contribution}

My own climate responsive building prototypes are intended to offer moments of experience that transcend the distant view of climate change into an immediate observation perceived by occupants of a space, building and the city [23]. By raising the awareness of people who are moving in and around the buildings and entwining their spatial perceptions with surfaces that are created with the spontaneous choreography of weather elements, I hope that people will be enthusiastic to take action towards energy reduction. The visual narrative has started with experiments with a thermal camera (Figure 1) and shows the energy exchange between buildings and the atmosphere as a vehicle to question built environments' contribution to climate change. Through 'Weathering Architecture (2008) and War(n/m)ing (2010)' performances involving an audience, the aim was to generate awareness of our dependence on central heating/cooling systems. Lighting is visible and therefore there is a direct correlation between the energy output and consumption when the lights are turned on/off. The general public is also well aware and informed about vehicles' contribution to greenhouse gases largely due to the visibility and smell of exhaust fumes. However, heating, cooling 
and the energy exchange between buildings and the atmosphere are invisible. The thermal camera gives temperature a color, ranging from hot, white, to cold, blue, picking up the inherent energy of buildings and objects that it is pointed at. Although mostly used for technical studies in engineering, architecture as well as in military, I have used the thermal camera images to give a visual presence to buildings' contribution to a warming atmosphere. In the above performances by showing the energy escaping from building surfaces, I have demonstrated that we are not just heating/cooling our buildings but the whole atmosphere thus providing a visual proof to the statement that Ian McEwin coins, as the 'hot breadth of our civilization'. Marshall McLuhan in a book entitled 'hot and cold', in his response to a collection of essays from critical writers, states that 'the heat steps up the tactile sense, diminishing the visual' [11]. By using the thermal camera output, buildings can be perceived not just as beautiful or ugly, static, visual constructs but as animate, hot and cold entities.

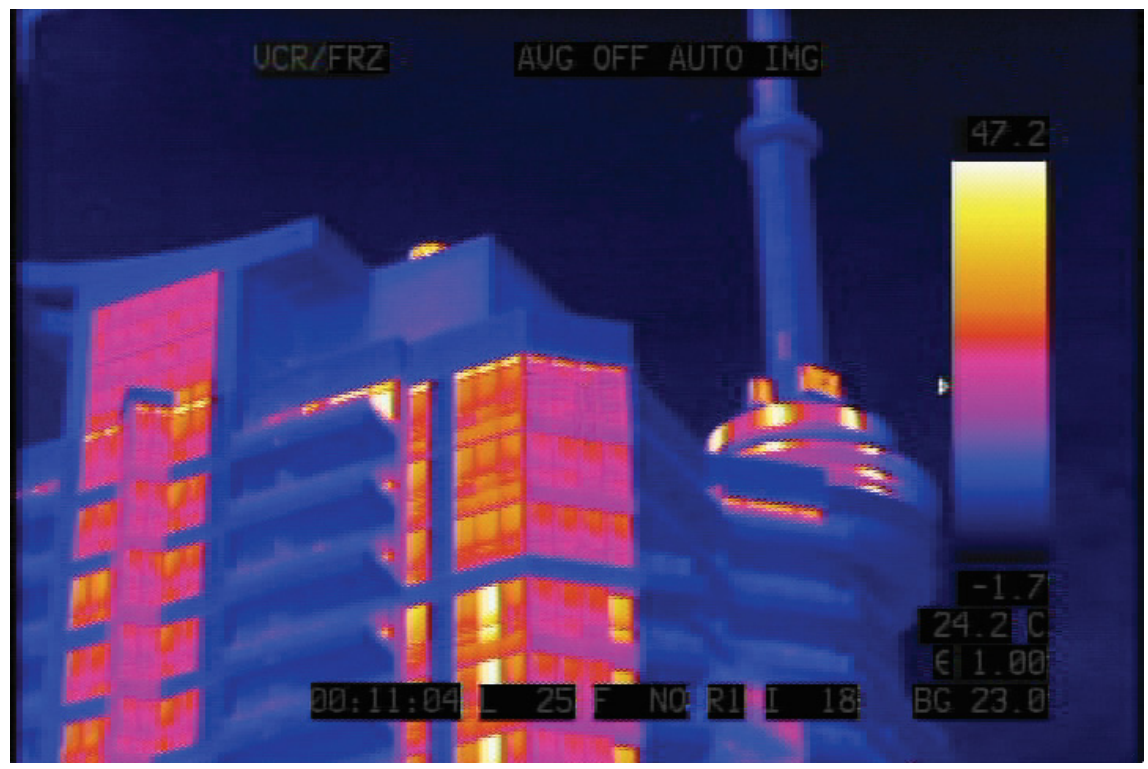

Figure 1: Thermal camera image, Toronto.

In the 'Weathering Architecture' installations, the overall goal is to raise awareness of architecture's impact on climate change by merging art, architecture and imaging technologies. Referencing works of innovators, artists, scientists, thinkers that align, I attempt to explore and capitalize upon possibilities offered by new/existing materials and imaging technologies to display my artistic vision within the context of Toronto's built environment. Using the 'Weathering Architecture' project frame as a vehicle and extrapolating ideas from historical and contemporary contexts where image, text and architecture are juxtaposed, my paper and prototypes emphasize a new vision and a social narrative combining developments in media facades and climate change. The emphasis here is not to 
advocate further integration of media with buildings, but to solicit and integrate appropriate technology to make people aware of changing climate/ environmental variables. For millennia, buildings have been designed and constructed to resist the elements of nature. We need to subvert this convention purposefully, not for frivolity of displaying images on buildings, but as the outcome of dedicated research and creative work that explores how material innovations and lighting in particular, might transform rigid architectural structures into responsive weather laboratories. We need to imagine materials that are capable of absorbing and using the impact of nature as a means of lessening an individual building's environmental footprint while creating weather driven kinetic art at the same time.

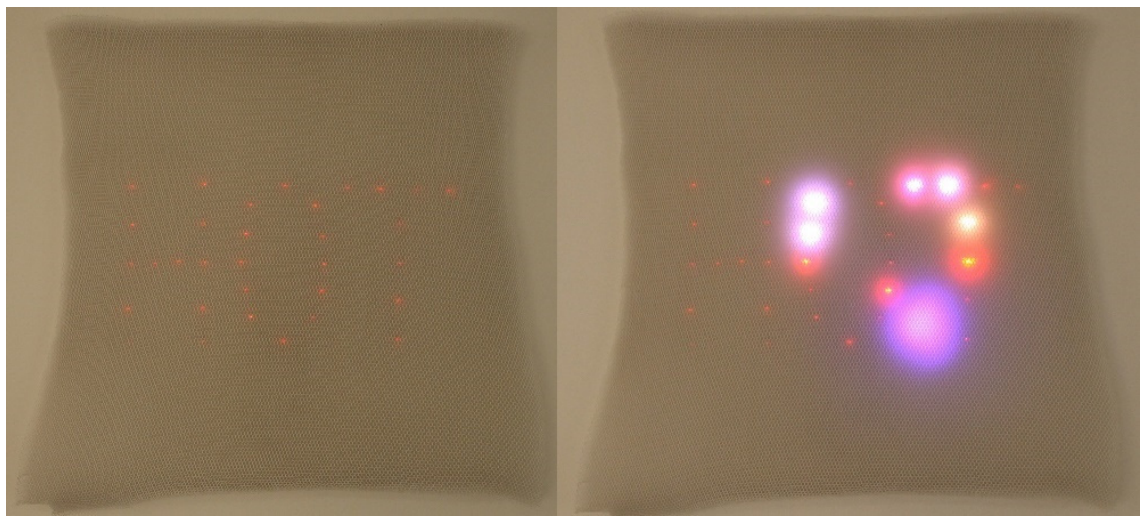

Figure 2: Temperature net.

By developing unique fibre-based and active coverings, skins and cladding for buildings, I have revealed the capacity to harness the four elements of Snow, Rain, Light and Wind [23] and document the findings in a methodical, yet creative and intriguing framework. Results of this work were displayed at 'Snow, Rain, Light, Wind: Weathering Architecture' exhibitions at the Triangle Gallery, Calgary (2010) the Design at Riverside Gallery, Cambridge (2009/2010), Angel Gallery (2012) and Ryerson Image Center, Toronto (2015). The exhibited prototypes, emphasizing materials' research and climate data from nano to mega-scale of a building, are conceived as building canvases that respond to weather elements, wash away, appear, disappear, reveal, scatter, accumulate and transform over time. Rather than mere visual constructions, to be judged solely and superficially as big/small or beautiful/ugly structures, buildings then can be perceived as "living" entities that can read, measure, or convert weather into energy fields to recover their environmental impact. An example is the Temperature Net prototype "Figure 2 " that sense temperature differences and displays the state of the building as 'hot' by integrating high intensity RGB LED modules and microcontrollers. Thus it is intended that the visceral connection to built environments and microclimate of a building can be revived through multi-sensory and ephemeral experiences, such as hot/cold, wet/dry, luminous/dark, and still/moving, tactile experience provided by the building surfaces. 
Over the past decade, my research umbrella and experimental prototypes evolved from integrating material innovations in built environments in a meaningful way towards materiality as 'responsive matter' in architecture and interiors. The notion of active building materiality, focusing on adaptability to variables in environmental conditions, and the diverse creative outputs will continue to be my long-term laboratory for making. My 'weathering architecture' prototypes expand with further research and experimentation with climate visualization and developments in media façade technology. I continue to challenge the widely accepted perception of material physicality as simply 'addon' or 'ornamental', in an effort to debate and lessen the impact of architecture and interiors on climate change. I am using imaging technology, climate data visualization, sensors and advanced prototyping methods, and integrate them with the media of film, installation art, and stage design to demonstrate climate responsive building concepts "Figure 3". The dissemination of this work in creative forms of architecture/interior installations, and 'façade prototypes' as well as the academic presentations emphasize conceptual building ideas and integrated technologies in particular, might transform rigid architectural structures into climate responsive, energy generating and ornate weather laboratories in our future practices.

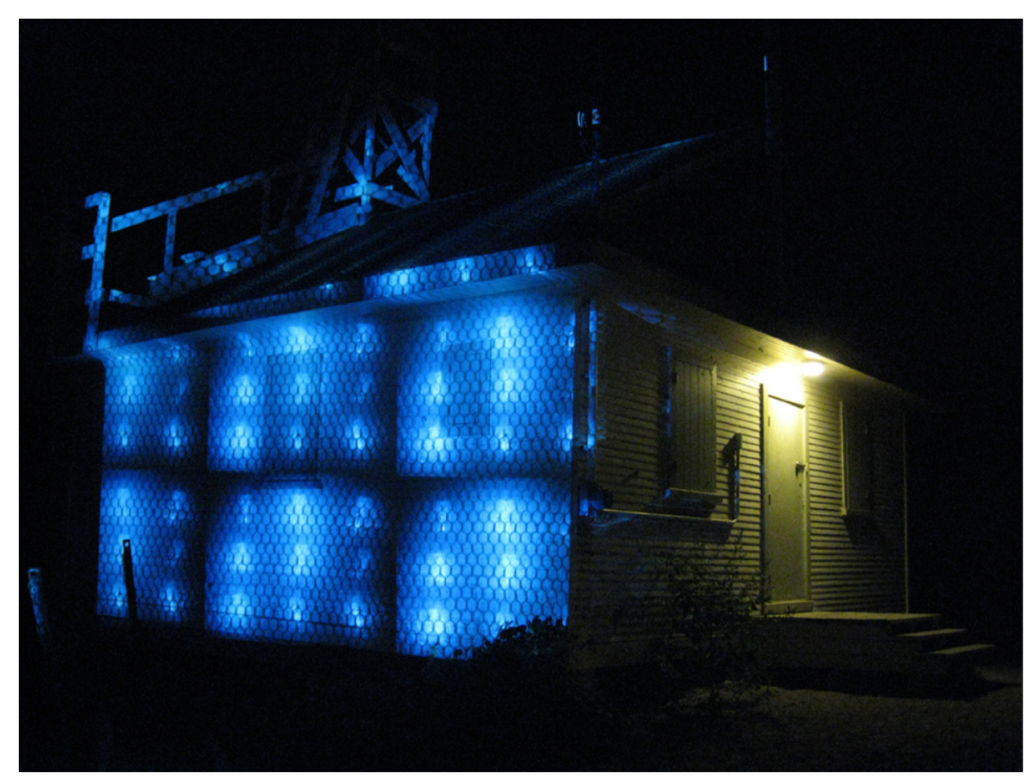

Figure 3: Heat net media façade.

\section{Conclusion}

These experiments demonstrate that media facades offer the potential to change the domain of architecture not as alternatives that replace existing static facades 
but as dynamic building systems that alter their behavior; capable of responding to mechanical, thermal, luminous, and acoustical energy fields. This approach to materiality as 'dynamic matter' in return can enhance our perceptions of the changing weather conditions and make us live more in tune with them rather than simply relying on mechanical systems to keep buildings at steady lighting/temperature levels that in return contribute to climate change. This way the discussion of built environments can be taken outside of the domain of ugly and beautiful and their association with static structure and form. We can visualize buildings as hot, cold, wet, dry, bright, dark, and malleable thus emphasizing their performance and transformation with weather conditions.

\section{Acknowledgements}

Funding provided by a Social Sciences and Humanities Research Council Canada, Research/Creation Grant, 2005-2010; and Ryerson University Faculty of Communication Design. In kind support provided by $3 \mathrm{M}$ Canada ${ }^{\mathrm{TM}}$, Toronto Harbourfront Centre, Gladstone Hotel, Cambridge Galleries and Triangle Gallery.

\section{References}

[1] Why The Building Sector? http://architecture2030.org/buildings_problem _why/

[2] Klein, N. 2015. This Changes Everything: Capitalism vs. the Climate. Vintage Canada: Toronto, pp. 461-465, 2015.

[3] Buckland, D. Burning Ice: Art \& Climate Change. Cape Farewell: London, Introduction \& pp. 10-11, 2006.

[4] McEwan, I. Solar: A Novel. Nan A. Talese/Doubleday: New York, 2010.

[5] Suzuki Diaries: Future City - The Nature of Things: Science, Wildlife and Technology-CBC-TV. 2013. www.cbc.ca/natureofthings/episodes/suzukidiaries-future-city

[6] Pallasmaa, J. The Eyes of the Skin: Architecture and the Senses. WileyAcademy: Chichester, 2005.

[7] Pallasmaa, J. The Architecture of Image: Existential Space in Cinema. Rakennustieto: Helsinki, p. 7, 2001.

[8] Hensel, M. Performance-oriented Architecture: Rethinking Architectural Design and the Built Environment. Wiley: Hoboken, NJ., pp. 57-67, 2013.

[9] Ball, P. Made to Measure: New Materials for the 21st Century. Princeton University Press: Princeton, NJ., p. 105, 1997.

[10] Moholy-Nagy, L., \& Hoffmann, D. M. The New Vision, From Material to Architecture. Brewer, Warren \& Putnam: New York, 1932.

[11] Stearn, G. E. (ed.). McLuhan: Hot \& Cold: A Primer for the Understanding of and a Critical Symposium with a Rebuttal. New American Library: Toronto, p. 41, 1969.

[12] Grynsztejn, M., Elíasson, O., Birnbaum, D., \& Speaks, M (eds.). Olafur Eliasson. Phaidon Press: London, 2002.

[13] Studio Olafur Eliasson. http://olafureliasson.net/ 
[14] Facades of Harpa Reykjavik Concert Hall. Studio Olafur Eliasson. http://olafureliasson.net/archive/artwork/WEK100668/facades-of-harpareykjavik-concert-hall-and-conference-centre

[15] Ned Kahn: Ned Kahn Studios. http://nedkahn.com/

[16] Waste-to-Energy Plant in Copenhagen by BIG. www.arcspace.com/features /big/waste-to-energy-plant/

[17] Realities:united. www.realities-united.de/

[18] Addington, D. M., \& Schodek, D. L. Smart Materials and New Technologies: For the Architecture and Design Professions. Architectural Press: Amsterdam, pp. 7-8, 2005.

[19] SmartWrap ${ }^{\mathrm{TM}}$ Building Envelope, KieranTimberlake. http://kieran timberlake.com/pages/view/28

[20] Klassen, F \& Kronenburg. R. (eds.). Transportable Environments 3. Taylor \& Francis: New York, pp. 124-125, 2006.

[21] SGP Architects. http://sgp-a.com/\#/cat/systems/

[22] Haeusler, M. H., Tomitsch, M., Tscherteu, G., \& Berkel, B. V. New Media Facades: A Global Survey. Media Architecture Institute: Ludwigsberg, pp. 196-197, 2012.

[23] Klassen, F. 2010. Snow, Rain, Light, Wind: Weathering Architecture. Hong Kong. 